\title{
Alternative salt bridge formation in $A \beta-a$ hallmark of early-onset Alzheimer's disease?
}

\author{
Maarten Schledorn ${ }^{1}$, Beat H. Meier ${ }^{1 *}$ and Anja Böckmann ${ }^{2 *}$ \\ ${ }^{1}$ Physical Chemistry, Eidgenössische Technische Hochschule Zürich, Zurich, Switzerland, ${ }^{2}$ Institut de Biologie et Chimie des \\ Protéines, Bases Moléculaires et Structurales des Systèmes Infectieux, Labex Ecofect, UMR 5086 CNRS, Université de \\ Lyon, Lyon, France
}

\section{OPEN ACCESS}

Edited by:

Annalisa Pastore,

King's College London, UK

Reviewed by:

Manuel Etzkorn,

Heinrich Heine University Düsseldorf

Germany

Piero Andrea Temussi, Università degli Studi di Napoli

Federico II, Italy

${ }^{*}$ Correspondence:

Beat H. Meier,

Physical Chemistry, Eidgenössische

Technische Hochschule Zürich,

Vladimir-Prelog-Weg 2, CH-8093

Zurich, Switzerland

beme@ethz.ch,

Anja Böckmann,

Centre National de la Recherche

Scientifique, Institut de Biologie et Chimie des Protéines, 7, passage du

Vercors, 69367 Lyon, France a.bockmann@ibcp.fr

Specialty section: This article was submitted to Structural Biology,

a section of the journal

Frontiers in Molecular Biosciences

Received: 20 February 2015 Accepted: 07 April 2015

Published: 28 April 2015

Citation:

Schledorn M, Meier BH and Böckmann A (2015) Alternative salt bridge formation in $A \beta$ - a hallmark of

early-onset Alzheimer's disease?

Front. Mol. Biosci. 2:14.

doi: 10.3389/fmolb.2015.00014
Recently the 3D structure of the Osaka mutant form (E22 $\Delta$ ) of Amyloid- $\beta 1-40$ has been determined. We here compare the NMR chemical-shift with the published shifts of a brain-seeded form of wild-type $A \beta$ and suggest that the determined mutant fold is accessible to the wild-type protein as well, with small conformational adaptations which accommodate the E22 residue missing in the Osaka mutant. In addition, we illustrate how other mutants could also conform to this model. The stabilization of the $\mathrm{N}$-terminal part of the protein via an intermolecular salt bridge to Lys28 may represent a common structural motif for the mutants which are related to early-onset Alzheimer disease. This feature might connect to the observed increased toxicity of the mutant forms compared to wild-type $A \beta 1-40$, where the salt bridge involving Lys28 is intramolecular.

Keywords: amyloid-beta, Osaka mutant, Alzheimer's disease, 3D structure, solid-state NMR

\section{Introduction}

Amyloid- $\beta(\mathrm{A} \beta)$ in its different conformations and aggregation states is a central player in the amyloid-cascade hypothesis for Alzheimer's disease (AD) (Hardy and Higgins, 1992). Brainderived or synthetic aggregates were shown to propagate between cells when injected into transgenic mice (Kane et al., 2000; Eisele et al., 2010). It is not established whether the A $\beta$ fibrils or smaller oligomers, or both, are the toxic species (Benilova et al., 2012; Cohen et al., 2013; Matsuzaki, 2014). The existence of mutants that lead to early onset AD (Wu et al., 2012) offers an opportunity to characterize the conformational space available to the $A \beta$ peptide in fibrillar or oligomeric state. Amyloids in general, and $\mathrm{A} \beta$ in particular, are known for their ability to form a number of polymorphs (Meier and Böckmann, 2015), and it has been proposed that they are at the origin of different phenotypes of the disease, reminiscent of the appearance of strains in prion disease (Meyer-Luehmann et al., 2006; Colby and Prusiner, 2011; Stöhr et al., 2012). Different mutant forms of $A \beta$ have been identified involving a single-residue deletion or substitution at or adjacent to residue E22, e.g., Flemish A21G (Hendriks et al., 1992), Arctic E22G (Kamino et al., 1992; Nilsberth et al., 2001), Dutch E22Q (Levy et al., 1990; Van Broeckhoven et al., 1990), Italian E22K (Tagliavini et al., 1999; Bugiani et al., 2010), Iowa D23N (Grabowski et al., 2001), and the Osaka deletion mutation E22 $\Delta$ (Tomiyama et al., 2008; Ovchinnikova et al., 2011). These mutants cause early-onset $\mathrm{AD}$, and they display different toxicity profiles in in vitro and in vivo studies compared to wild-type $A \beta 1-40$ and $A \beta 1-42$.

Knowledge of the atomic-resolution 3D structure is central for the understanding of the molecular basis underlying the amyloid diseases, and solid-state NMR is a powerful method to determine and characterize structures of amyloid fibrils at atomic resolution (Wasmer et al., 2008) 


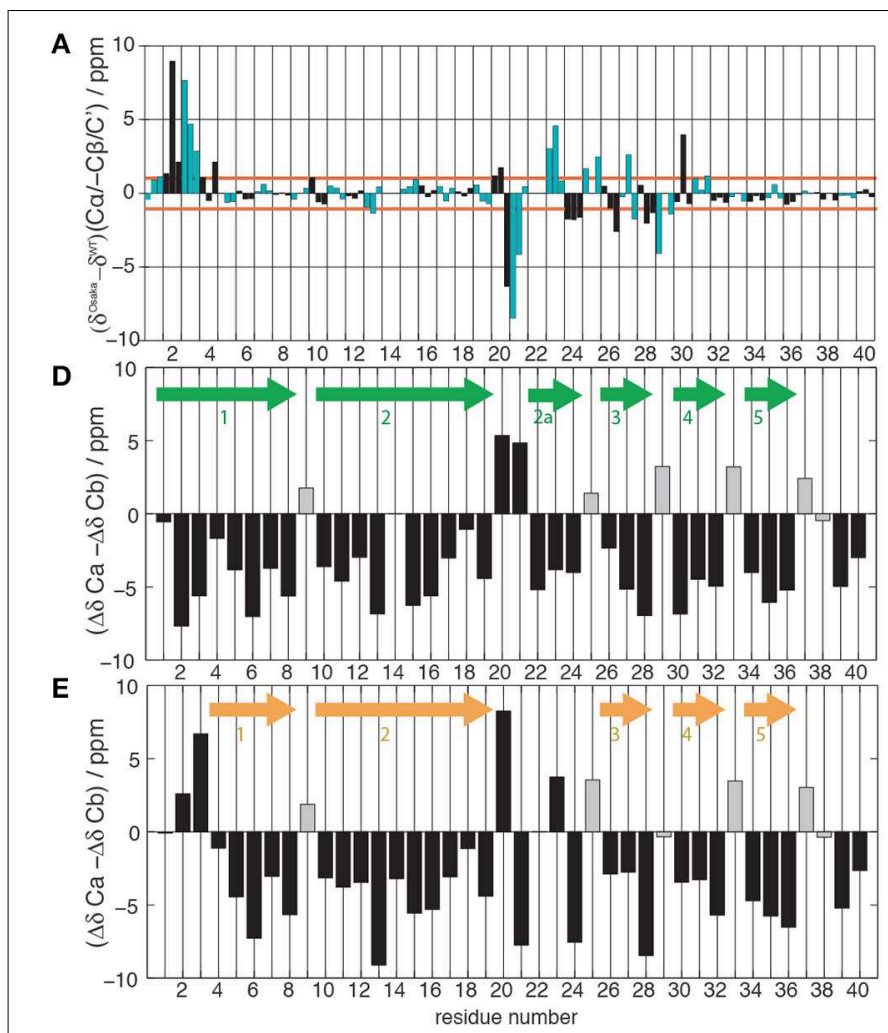

FIGURE 1 | (A) Difference between the chemical shifts $\mathrm{C} \alpha,-\mathrm{C} \beta$ and C' between the Osaka mutant (Schütz et al., 2015) and wild-type A $\beta$ 1-40, Patient I of Lu et al. (2013). C $\beta$ is given with negative values to highlight differences in secondary structure propensity where all chemical-shift differences point in the same direction; where the Osaka mutant shows less $\beta$-strand structure, all three values are positive, and vice versa. The chemical shifts are re-referenced to yield the smallest possible

differences. Even residues are shown in black, odd ones in cyan. (B) Average absolute values of the mean chemical shift differences between wild-type A 1 1-40 (Lu et al., 2013) and the Osaka mutant (Schütz et al.,
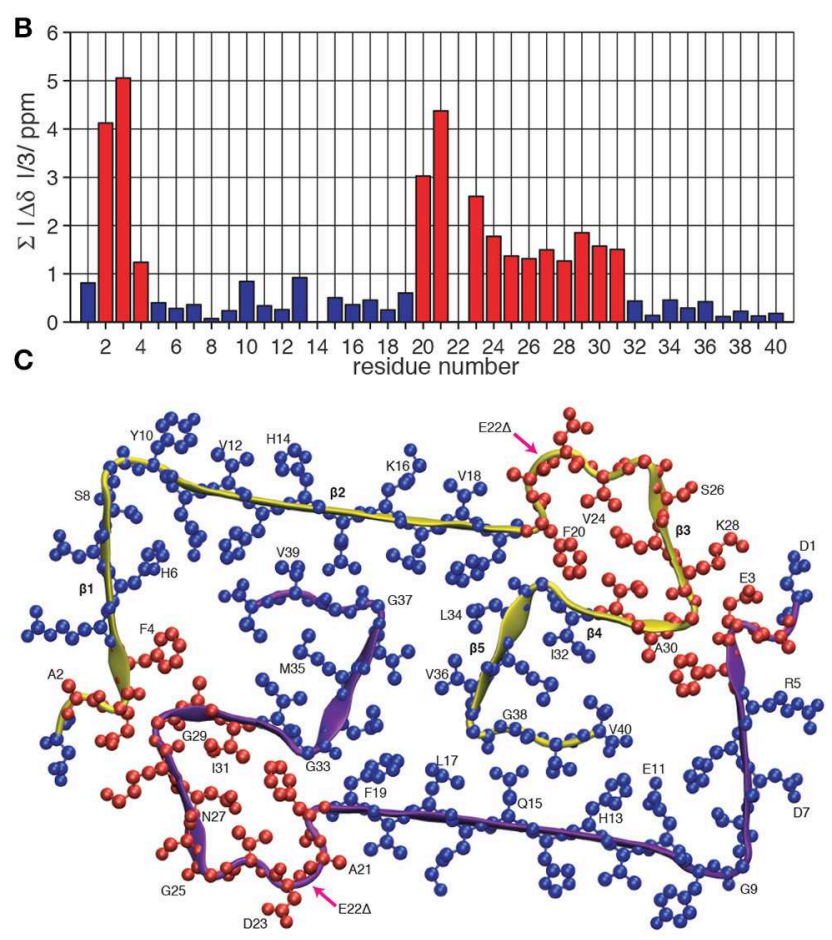

2015), $\left(\left|\delta C \alpha^{W T}-\delta C \alpha^{\text {Osaka }}\right|+\left|\delta C \beta^{W T}-\delta C \beta^{\text {Osaka }}\right|+\right.$ $\left.\left|\delta C^{\prime W T}-\delta C^{\prime O s a k a}\right|\right) / 3$. Deviations larger than $1 \mathrm{ppm}$ are plotted in red, those smaller in blue. (C) Representation of chemical-shift differences from (B) plotted on the A $\beta 1-40$ E22 $\Delta$ structure (pdb entry 2MVX). Same color coding as in (B). Differences between $\mathrm{C} \alpha$ and $\mathrm{C} \beta$ secondary chemical shifts for (D) wild-type A $\beta$ 1-40 Patient I of Lu et al. (2013) and (E) the Osaka mutant (Schütz et al., 2015). Arrows indicate locations of $\beta$-sheets according to the rule that three negative values in a row are indicative for this secondary structure element, with the exception of glycines which are marked by a gray bar color. and to map the conformational space available to these proteins. In addition to the Osaka mutant structure, (Schütz et al., 2015) several wild-type $A \beta$ fibril polymorphs have been characterized (Petkova et al., 2002; Paravastu et al., 2008; Bertini et al., 2011; Lopez del Amo et al., 2012; Lu et al., 2013; Niu et al., 2014), and a model for the Iowa mutant was presented (Sgourakis et al., 2015).

Despite a large body of literature, there is presently not enough high-resolution structural data available to establish a detailed structure-toxicity relationship for amyloids in general, and $\mathrm{A} \beta$ in particular (Tiller and Tessier, 2013). However, virtually complete chemical-shift information for all 40 residues has recently become available for two wild-type and a mutant form of $A \beta 1-40$. We use this information here to suggest, on the basis of a comparison of NMR chemical-shift values between the Osaka mutant (Huber et al., 2014; Schütz et al., 2015) and one of the wild-type polymorphs (Lu et al., 2013), that the wild-type peptide has indeed the ability to assume the fold established for $A \beta 1-40$ E22 $\Delta$ (Schütz et al., 2015), albeit with a modified in-out pattern of the amino-acid residues in the loop comprising residues 2031. Furthermore, we illustrate how other early-onset $A \beta$ mutants can in principle form a similar fold. We speculate that the key feature of the mutant folds is the formation of an intermolecular salt bridge, attaching the N-terminal residues to the fibril core, as opposed to the wild-type protein, where the situation is substantially different, as residue K28 was experimentally shown to be involved in an intramolecular salt bridge (Lu et al., 2013). As a consequence, the $\mathrm{N}$-terminus is less tightly attached, which impacts fibril properties, and potentially those of prefibrillar states (Tarus et al., 2006; Reddy et al., 2009).

\section{Materials and Methods}

\section{Calculation of the Model for the WT A $\beta$ Dimer}

The calculation was performed as described for the "manual calculations" in reference (Schütz et al., 2015). For residues 2-4, and 20-31, TALOS + angles were calculated from the deposited chemical shifts (Lu et al., 2013). Unambiguous distance restraints, as determined in Schütz et al. (2015) for the mutant form, were used for the residues which show concomitant chemical shifts in both proteins (blue residues in Figure 1C). The list of 

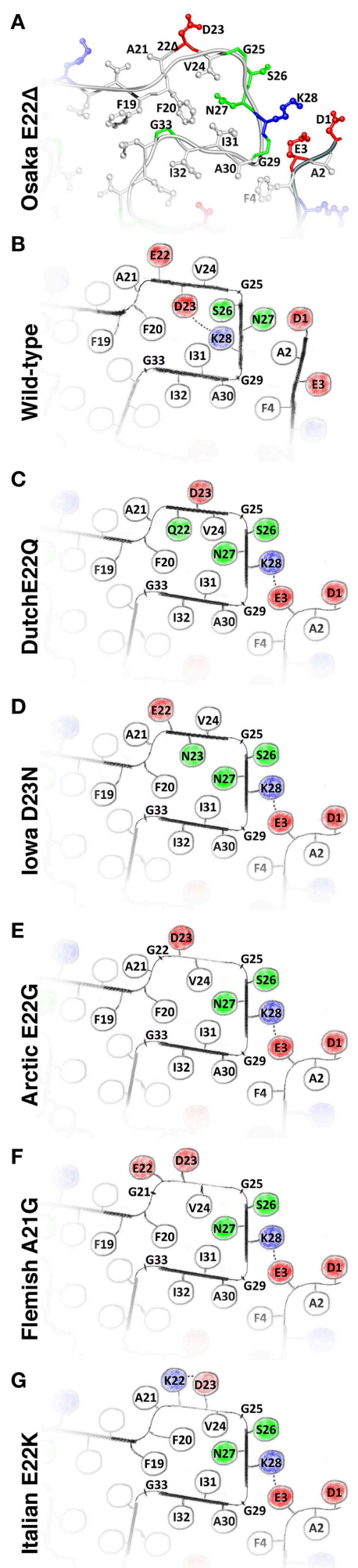

FIGURE 2 | (A) The structure of the Osaka mutant E22 $\Delta$ from Schütz et al. (2015); (B) speculative model of WT A $\beta$ as described in the main text; and hypothetical models of (C) Dutch mutant E22Q; (D) lowa mutant D23N; (E) Arctic mutant E22G; (F); Flemish mutant A21G; and (G) Italian mutant E22K.

(Continued)

\section{FIGURE 2 | Continued}

Models (C-G) are built based on the Osaka mutant structure and additional considerations as described in the main text. All these mutants favor, in this model, an outside orientation of K28. Hydrophobic residues are colored white, glycines and polar residues are green, and charged residues are colored blue when positive and red when negative.

distance restraints used is therefore a subset of the list given in Schütz et al. (2015), namely the ones between two residues from the range $1,5-19,32-40$, and is listed in Table S1. The orientations of the $\beta$-strands were defined for $\beta$-sheets $1,2,4$, and 5 in the same manner as in the mutant form (for the strand numbering see Figures 1D-E). This input was not sufficient to distinguish between the possible orientations of the two $\beta$ strands spanning residues E22-V24 (strand 2a) and S26-K28 (strand 3) in the wild-type protein (Figure 1D) on the basis of restraint violations. The following additional considerations were used as constraints for the structure calculations: (i) The assigned side-chain $C \gamma / \delta$ chemical shifts in the brain-seeded WT polymorph for D23 and E22 respectively show chemicalshift values typical of charged $\mathrm{COO}^{-}$side-chain moieties ( $\mathrm{Lu}$ et al., 2013). (ii) The $\beta$-sheet structure of E22-V24 evidenced by the secondary chemical shifts (Figure 1D) observed for the brain-seeded WT polymorph implies that either E22 or D23 point to the inside of the fibril. (iii) The thus introduced E22 or D23 negative charge inside the fibril should be compensated by a positive charge in order to yield a stable fibril. Here, K28 is the only possible partner. From these three points, we can infer that S26-K28 shows an in-out-in pattern, allowing for charge compensation. This leaves the two options of an out-in-out or in-out-in orientation for E22-V24, but steric clashes between V24 and S26 (in an in-out-in orientation of E22-V24) strongly suggest an out-in-out pattern, with D23 pointing inside. And indeed, the D23-K28 salt bridge has been described in most WT models (Paravastu et al., 2006; Lu et al., 2013).

\section{Structural Models for the Mutants}

For all mutant form models, dihedral angle restraints from Schütz et al. (2015) were used and distance restraints from the same source were entered into CYANA calculations, except for residues 20-30 and 2-4. Hydrogen bonding patterns were adopted from the Osaka mutant for the Arctic, Flemish and Italian mutant. Like the WT model, the Dutch and Iowa mutant calculations included an additional $\beta$-sheet $2 \mathrm{a}$ for residues $22-24$ (see Figure 1D). Its orientation followed from two arguments: (i) we avoid uncompensated charges inside the core of the fibril, and (ii) we avoid steric clashes between residues V24 and S26. As a result, the Iowa mutant has an out-in-out pattern (Figure 2D and Figure S2C), as also predicted in a recent model for the Iowa mutant (Sgourakis et al., 2015). While the Dutch mutant assumes an in-out-in pattern for residues Q22-V24 (Figure 2C and Figure S2B), the Arctic mutant shows an outside-pointing D23 (Figure 2E and Figure S2D), and in the Flemish mutant both E22 and D23 are oriented outwards and $\beta$-strand E22-V24 is not present (Figure 2F and Figure S2E). Finally, in the Italian 
TABLE 1 | Information used as input for WT model building.

\begin{tabular}{|c|c|c|c|c|}
\hline & \multicolumn{3}{|c|}{ Residues 5-19 and 32-40 } & Residues 1-4 and $20-31$ \\
\hline Distance restraints & \multicolumn{3}{|c|}{ Inter/Intra-molecularly and spectrally unambiguous restraints } & None \\
\hline TALOS+ angles & \multicolumn{3}{|c|}{ BMRB 25289 (Schütz et al., 2015) } & BMRB 19009 (Lu et al., 2013) \\
\hline \multirow[t]{2}{*}{ Sequence } & 1 & 10 & 20 & 30 \\
\hline & DAEFRHDSG & YEVHHQKLVF & FAEDVGSNKG & AIIGLMVGGVV \\
\hline
\end{tabular}

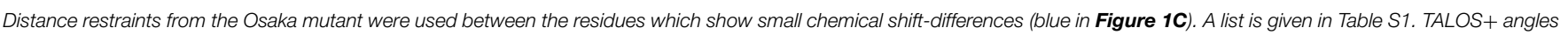

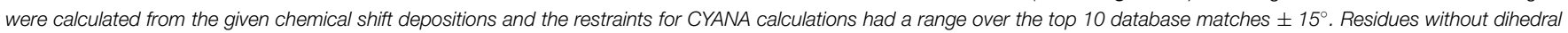

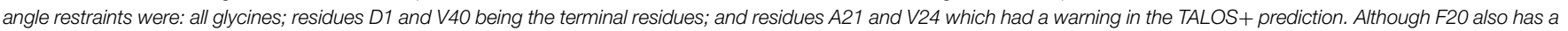

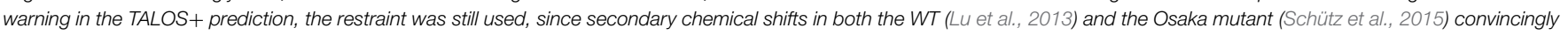

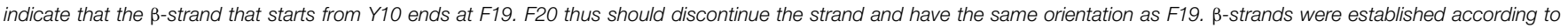

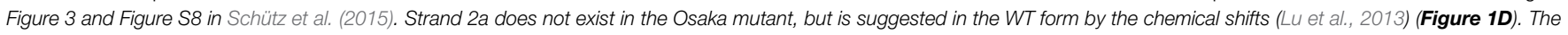

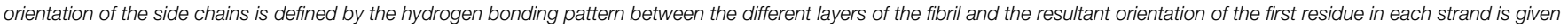
as inward or outward with respect to the core of the dimer.

mutant (Figure 2G and Figure S2F), we force the formation of a K22-D23 salt bridge by adding a restraint to the CYANA where no electrostatic interactions are considered. Without restraint violations, this residue pair can only be accommodated outside the loop due to limited space on the inside. The structural statistics for all mutant calculations as well as the wildtype is given in Table S2.

\section{Results and Discussion}

\section{The Wild-Type Protein Can Adopt a Similar Fold as the Osaka Mutant}

Chemical-shift comparisons between proteins represent a sensitive means to assess differences and similarities in 3D structures, as shift differences point to conformational differences for the observed residue. Comparison of wild-type $A \beta$ chemical shifts described by Lu et al. (2013) to those of the A $\beta 1-40$ E22 $\Delta$ mutant (Schütz et al., 2015) (Figure 1A) reveals that the two forms display almost coincident shifts for large parts of the protein, with noticeable exceptions in two regions where the differences surpass the $1 \mathrm{ppm}$ limit which we consider to be a significant change.

To illustrate the location of these changes, we plotted the absolute value of the mean chemical-shift differences from Figure 1A, displayed in Figure 1B, on the A $\beta$ E22 $\Delta$ mutant structure in Figure 1C: residues with similar shifts are colored in blue, others in red. Blue residues cover the entire hydrophobic core, as well as the largest parts of $\beta$-sheets 1 and 2 . Importantly, the two regions displaying larger chemical-shift differences are distant in sequence, but spatially contiguous if plotted on the A $\beta$ E22 $\Delta$ mutant structure. They concern the loop as well as the N-terminus attached to the loop via the E3-K28 salt bridge. For comparison, the other wild-type polymorph with complete assignments (Bertini et al., 2011) shows substantial chemical-shift differences spanning the entire sequence, with only few and possibly fortuitous exceptions (see Supplementary Figures S1A-C).

\section{Comparison of Secondary Structural Features of WT $A \beta$ and the Osaka Mutant}

Secondary chemical shifts [the difference to random-coil shifts (Bax, 1991; Wishart and Sykes, 1994)] inform on protein secondary structures. The secondary shift differences $\Delta \delta \mathrm{C} \alpha$ $\triangle \delta C \beta$ can be evaluated according to a pattern of three consecutive negative values corresponding to a $\beta$-strand, four positive values in a row indicating $\alpha$-helical secondary structure, and the remainder turns or loops. $\Delta \delta C \alpha-\Delta \delta C \beta$ of $A \beta 1-40$ and $\mathrm{A} \beta 1-40$ E22 $\Delta$ is plotted in Figures 1D,E and the resulting pattern of $\beta$-sheets is found to be quite similar, with a couple of noticeable differences: for residues A2 and G3, where the mutant protein structure presents a turn, the WT protein chemical shifts indicate a straight $\beta$-strand, extending the strand which in A $\beta 1-40$ E22 $\Delta$ spans residues F4 to $\mathrm{S} 8$. The turn comprising residues F20-V24 in the mutant form is reduced, in the WT peptide, to residues F20-A21, and an additional $\beta$-strand, E22-V24 is present. We note from Figure 1 that the $\beta$-sheet S26-K28 is conserved, but that the individual chemical shifts (Figure 1A) differ significantly (>1 ppm). Residues F4-F19 and residues I30-V40 feature very similar shifts for the WT and the Osaka-mutant fibril.

\section{A Speculative Structure for a WT A $\beta$ Polymorph}

We have noted that the monomer conformation for the residues mentioned above is very similar for the WT from the brain-seeded sample and the Osaka mutation despite the fact that the polymorph of the mutant form is described by a two-fold symmetry (Schütz et al., 2015) and the WT polymorph by a three-fold symmetry (Lu et al., 2013). In the following, we construct a two-fold model of a monomer in a WT fibril using the information provided in Table 1. The model mainly relies on the data coming from the mutant form, complemented by information from the brain seeded WT form for the residues showing chemical shift differences between the two forms. Details are given in the Materials and Methods Section. The corresponding calculation resulted in no restraint violations, and the atomic-detail model is displayed 
for information in Figure S2. Figure 2B represents the region of interest as a schematic drawing, in order to emphasize its nature as a speculative model. When compared to the Osaka mutant structure shown in Figure 2A, the two $\beta$-sheets E22-V24 and S26-K28 in this model are turned around (inside/outside interchanged) to accommodate the K28-D23 salt bridge inside the loop (see Materials and Methods Section). The attachment of $\beta$-sheet 1 (Figure 1C) is now only mediated by the H6E11-E13-V40 salt bridge network (Schütz et al., 2015), as well as F4-A30 hydrophobic interactions, and lacks the strong electrostatic stabilization by E3-K28. This would explain the dynamic nature of the $\mathrm{N}$-terminal part, roughly 10 residues, which has systematically been observed in the WT forms. These residues were shown to display a certain flexibility (allowing for $\mathrm{H} / \mathrm{D}$ exchange or giving raise to weak or missing signals in solidstate NMR spectra) in most polymorphs described, and could only be sequentially assigned for A $\beta 1-40$ E22 $\Delta$ and three wildtype models (Bertini et al., 2011; Lu et al., 2013; Niu et al., 2014). Even in these, no unambiguous distance restraints could be established between the $\mathrm{N}$-terminal segment and the fibril core. Only the A $\beta 1-40$ E22 $\Delta$ mutant distinguishes itself by a rigid $\mathrm{N}$-terminal segment, structurally unambiguously defined by the intermolecular E3-K28 salt bridge. We speculate that this stabilizing salt bridge is a direct consequence of the E22 $\Delta$ mutation, and we illustrate in the following how it might occur as well in other early-onset $\mathrm{AD}$ related $\mathrm{A} \beta$ variants, where mutations are found in the in the loop around residue A21-D23.

\section{Structural Models for Other Mutant Forms}

A common feature shared by all the here discussed early-onset mutants is that their amino-acids composition is such that the presence of a negative charge in the fibril interior can be avoided, which in turn allows an outside orientation of Lys28 and a rigidification of the $\mathrm{N}$-terminal $\beta$-strand by its attachment to the fibril core via the E3-K28 salt bridge. Hypothetical models for the different mutant forms are shown in Figure S2 (for details of the calculations, see Materials and Methods Section), and drawings of the regions of interest are shown in Figures 2C-G. The Dutch, Iowa and Arctic mutants all result in the replacement of a negative charge of the wild-type peptide, either D23 or E22, by a polar residue, which easily accommodates then a chargefree fibril interior in the loop encompassing residues 20-31.

\section{References}

Bax, A. (1991). Empirical correlation between protein backbone conformation and $\mathrm{C}$-alpha and C-beta C-13 nuclear-magnetic-resonance chemical-shifts. J. Am. Chem. Soc. 113, 5490-5492.

Benilova, I., Karran, E., and De Strooper, B. (2012). The toxic A $\beta$ oligomer and Alzheimer's disease: an emperor in need of clothes. Nat. Publ. Group 15, 349-357. doi: 10.1038/nn.3028

Bertini, I., Gonnelli, L., Luchinat, C., Mao, J., and Nesi, A. (2011). A new structural model of A $\beta 40$ fibrils. J. Am. Chem. Soc. 133, 16013-16022. doi: $10.1021 /$ ja2035859

Bugiani, O., Giaccone, G., Rossi, G., Mangieri, M., Capobianco, R., Morbin, M., et al. (2010). Hereditary cerebral hemorrhage with amyloidosis associated with the E693K mutation of APP. Arch. Neurol Chic. 67, 987-995. doi: 10.1001/archneurol.2010.178
In the Flemish mutant, the $\mathrm{A} 21 \mathrm{G}$ mutation introduced additional flexibility, which can accommodate an outside orientation of both E22 and D23. In the Italian mutant, replacement of E22 by a positive charge (K22) allows to stabilize D23 outside by a salt bridge with K22. The calculations carried out for the mutant forms (Figure S2) show that the above discussed hypothetical conformations can be realized without steric hindrance.

\section{Conclusion}

In summary, while we cannot ascertain from our calculations that Lys 28 must be pointing outside in the early onset $A \beta$ mutants discussed here, we could show that there are no restraint violations, static clashes or unbalanced charges inside the loop when Lys28 points outside. Consequently, the residue can engage in an energetically favorable salt bridge with the N-terminus of the protein. The Osaka polymorph fold is thus in principle accessible to the other mutant forms, and the possibility to assume this fold could be of importance to early onset. In any case, the models presented here provide presently testable hypotheses in mutational studies allowing to experimentally confirm the central role of K28 in the increased toxicity of mutant forms (Levy et al., 1990; Van Broeckhoven et al., 1990; Hendriks et al., 1992; Tagliavini et al., 1999; Grabowski et al., 2001; Nilsberth et al., 2001; Tomiyama et al., 2008; Bugiani et al., 2010). More chemical-shift information and high-resolution structures of different polymorphs of WT $\mathrm{A} \beta$ and mutant fibrils of both $\mathrm{A} \beta$ 1-40 and 1-42 and, hopefully, oligomers (Stroud et al., 2012), will be needed to reliably establish a clear relationship between structure and biological activity of the protein.

\section{Acknowledgments}

This work has been supported by the Swiss National Science Foundation SNF (grant 200020_134681, 200020_146757), and the CNRS (ANR-12-BS08-0013-01, ANR-11-BSV8-021-01).

\section{Supplementary Material}

The Supplementary Material for this article can be found online at: http://journal.frontiersin.org/article/10.3389/fmolb. 2015.00014/abstract

Cohen, S. I. A., Linse, S., Luheshi, L. M., Hellstrand, E., White, D. A., Rajah, L., et al. (2013). Proliferation of amyloid- $\beta 42$ aggregates occurs through a secondary nucleation mechanism. Proc. Natl. Acad. Sci. U.S.A. 110, 9758-9763. doi: $10.1073 /$ pnas. 1218402110

Colby, D. W., and Prusiner, S. B. (2011). Prions. Cold Spring Harb. Perspect. Biol. 3:a006833. doi: 10.1101/cshperspect.a006833

Eisele, Y. S., Obermueller, U., Heilbronner, G., Baumann, F., Kaeser, S. A., Wolburg, H., et al. (2010). Peripherally applied a beta-containing inoculates induce cerebral beta-amyloidosis. Science 330, 980-982. doi: $10.1126 /$ science. 1194516

Grabowski, T. J., Cho, H. S., Vonsattel, J. P., Rebeck, G. W., and Greenberg, S. M. (2001). Novel amyloid precursor protein mutation in an Iowa family with dementia and severe cerebral amyloid angiopathy. Ann. Neurol. 49, 697-705. doi: 10.1002/ana. 1009 
Hardy, J., and Higgins, G. (1992). Alzheimer's disease: the amyloid cascade hypothesis. Science 256, 184-185. doi: 10.1126/science.1566067

Hendriks, L., van Duijn, C., Cras, P., Cruts, M., van Hul, W., van Harskamp, F., et al. (1992). Presenile dementia and cerebral haemorrhage linked to a mutation at codon 692 of the $\beta$-amyloid precursor protein gene. Nat. Genet. 1, $218-221$.

Huber, M., Ovchinnikova, O. Y., Schütz, A. K., Glockshuber, R., Meier, B. H., and Böckmann, A. (2014). Solid-state NMR sequential assignment of Osakamutant amyloid-beta (A $\beta 1-40$ E22 $\Delta$ ) fibrils. Biomol. NMR Assign. 9, 7-14. doi: 10.1007/s12104-013-9535-x

Kamino, K., Orr, H. T., Payami, H., Wijsman, E. M., Alonso, M. E., Pulst, S. M., et al. (1992). Linkage and mutational analysis of familial Alzheimer disease kindreds for the APP gene region. Am. J. Hum. Genet. 51, 998-1014.

Kane, M. D., Lipinski, W. J., Callahan, M. J., Bian, F., Durham, R. A., Schwarz, R. D., et al. (2000). Evidence for seeding of beta-amyloid by intracerebral infusion of Alzheimer brain extracts in beta-amyloid precursor protein-transgenic mice. J. Neurosci. 20, 3606-3611.

Levy, E., Carman, M. D., Fernandez-Madrid, I. J., Power, M. D., Lieberburg, I., van Duinen, S. G., et al. (1990). Mutation of the Alzheimer's disease amyloid gene in hereditary cerebral hemorrhage, Dutch type. Science 248, 1124-1126. doi: $10.1126 /$ science. 2111584

Lopez del Amo, J.-M., Schmidt, M., Fink, U., Dasari, M., Fändrich, M., and Reif, B. (2012). An asymmetric dimer as the basic subunit in Alzheimer's disease amyloid $\beta$ fibrils. Angew. Chem. Int. Ed Engl. 51, 6136-6139. doi: 10.1002/anie.201200965

Lu, J.-X., Qiang, W., Yau, W.-M., Schwieters, C. D., Meredith, S. C., and Tycko, R. (2013). Molecular structure of beta-amyloid fibrils in Alzheimer's disease brain tissue. Cell 154, 1257-1268. doi: 10.1016/j.cell.2013.08.035

Matsuzaki, K. (2014). How do membranes initiate Alzheimer's Disease? formation of toxic amyloid fibrils by the amyloid $\beta$-protein on ganglioside clusters. Acc. Chem. Res. 47, 2397-2404. doi: 10.1021/ar500127z

Meier, B. H., and Böckmann, A. (2015). ScienceDirectThe structure of fibrils from "misfolded" proteins. Curr. Opin. Struct. Biol. 30, 43-49. doi: 10.1016/j.sbi.2014.12.001

Meyer-Luehmann, M., Coomaraswamy, J., Bolmont, T., Kaeser, S., Schaefer, C., Kilger, E., et al. (2006). Exogenous induction of cerebral betaamyloidogenesis is governed by agent and host. Science 313, 1781-1784. doi: $10.1126 /$ science. 1131864

Nilsberth, C., Westlind-Danielsson, A., Eckman, C. B., Condron, M. M., Axelman, K., Forsell, C., et al. (2001). The 'Arctic'APP mutation (E693G) causes Alzheimer's disease by enhanced A[beta] protofibril formation. Nat. Neurosci. 4, 887-893. doi: 10.1038/nn0901-887

Niu, Z., Zhao, W., Zhang, Z., and Xiao, F. (2014). The molecular structure of Alzheimer $\beta$-amyloid fibrils formed in the presence of phospholipid vesicles. Angew. Chemie 35, 9294-9297. doi: 10.1002/anie.201311106

Ovchinnikova, O. Y., Finder, V. H., Vodopivec, I., Nitsch, R. M., and Glockshuber, R. (2011). The Osaka FAD mutation E22 $\Delta$ leads to the formation of a previously unknown type of amyloid $\beta$ fibrils and modulates $A \beta$ neurotoxicity. J. Mol. Biol. 408, 780-791. doi: 10.1016/j.jmb.2011.02.049

Paravastu, A. K., Leapman, R. D., Yau, W.-M., and Tycko, R. (2008). Molecular structural basis for polymorphism in Alzheimer's beta-amyloid fibrils. Proc. Natl. Acad. Sci. U.S.A. 105, 18349-18354. doi: 10.1073/pnas.0806270105

Paravastu, A., Petkova, A., and Tycko, R. (2006). Polymorphic fibril formation by residues 10-40 of the Alzheimer's \{beta\}-amyloid peptide. Biophys. J. 90, 4618-4629. doi: 10.1529/biophysj.105.076927

Petkova, A., Ishii, Y., Balbach, J., Antzutkin, O., Leapman, R., Delaglio, F., et al. (2002). A structural model for Alzheimer's \{beta\}-amyloid fibrils based on experimental constraints from solid state NMR. Proc. Natl. Acad. Sci. U.S.A. 99, 16742-16747. doi: 10.1073/pnas.262663499

Reddy, G., Straub, J. E., and Thirumalai, D. (2009). Influence of preformed Asp23Lys28 salt bridge on the conformational fluctuations of monomers and dimers of $\mathrm{A} \beta$ Peptides with implications for rates of fibril formation. J. Phys. Chem. B 113, 1162-1172. doi: 10.1021/jp808914c

Schütz, A. K., Vagt, T., Huber, M., Ovchinnikova, O. Y., Cadalbert, R., Wall, J., et al. (2015). Atomic-resolution three-dimensional structure of amyloid $\beta$ fibrils bearing the osaka mutation. Angew. Chem. Int. Ed. Engl. 54, 331-335. doi: 10.1002/anie. 201408598

Sgourakis, N. G., Yau, W.-M., and Qiang, W. (2015). Modeling an inregister, parallel "iowa" A\&beta; fibril structure using solid-state NMR data from labeled samples with rosetta. Struct. Fold. Des. 23, 216-227. doi: 10.1016/j.str.2014.10.022

Stöhr, J., Watts, J. C., Mensinger, Z. L., Oehler, A., Grillo, S. K., DeArmond, S. J., et al. (2012). Purified and synthetic Alzheimer's amyloid beta (A $\beta$ ) prions. Proc. Natl. Acad. Sci. U.S.A. 109, 11025-11030. doi: 10.1073/pnas.1206555109

Stroud, J. C., Liu, C., Teng, P. K., and Eisenberg, D. (2012). Toxic fibrillar oligomers of amyloid- $\beta$ have cross- $\beta$ structure. Proc. Natl. Acad. Sci. U.S.A. 109, 7717-7722. doi: 10.1073/pnas.1203193109

Tagliavini, F., Rossi, G., Padovani, A., Magoni, M., Andora, G., Sgarzi, M., et al. (1999). A new app mutation related to hereditary cerebral haemorrhage. Alzheimers Rep. 2, S28.

Tarus, B., Straub, J. E., and Thirumalai, D. (2006). Dynamics of Asp23-Lys28 saltbridge formation in A $\beta$ 10-35monomers. J. Am. Chem. Soc. 128, 16159-16168. doi: $10.1021 /$ ja064872y

Tiller, K. E., and Tessier, P. M. (2013). Lifting the veil on amyloid drug design. eLife 2:e01089. doi: 10.7554/eLife.01089

Tomiyama, T., Nagata, T., Shimada, H., Teraoka, R., Fukushima, A., Kanemitsu, H., et al. (2008). A new amyloid $\beta$ variant favoring oligomerization in Alzheimer's-type dementia. Ann. Neurol. 63, 377-387. doi: 10.1002/ana. 21321

Van Broeckhoven, C., Haan, J., Bakker, E., Hardy, J. A., van Hul, W., Wehnert, A., et al. (1990). Amyloid beta protein precursor gene and hereditary cerebral hemorrhage with amyloidosis (Dutch). Science 248, 1120-1122. doi: 10.1126/science. 1971458

Wasmer, C., Lange, A., van Melckebeke, H., Siemer, A. B., Riek, R., and Meier, B. H. (2008). Amyloid fibrils of the HET-s(218-289) prion form a beta solenoid with a triangular hydrophobic core. Science 319, 1523-1526. doi: 10.1126/science.1151839

Wishart, D. S., and Sykes, B. D. (1994). The 13C chemical-shift index: a simple method for the identification of protein secondary structure using $13 \mathrm{C}$ chemical-shift data. J. Biomol. NMR 4, 171-180. doi: 10.1007/BF00175245

Wu, L., Rosa-Neto, P., Hsiung, G.-Y. R., Sadovnick, A. D., Masellis, M., Black, S. E., et al. (2012). Early-onset familial Alzheimer's disease (EOFAD). Can. J. Neurol. Sci. 39, 436-445. doi: 10.1017/S0317167100013949

Conflict of Interest Statement: The authors declare that the research was conducted in the absence of any commercial or financial relationships that could be construed as a potential conflict of interest.

Copyright (C) 2015 Schledorn, Meier and Böckmann. This is an open-access article distributed under the terms of the Creative Commons Attribution License (CC BY). The use, distribution or reproduction in other forums is permitted, provided the original author(s) or licensor are credited and that the original publication in this journal is cited, in accordance with accepted academic practice. No use, distribution or reproduction is permitted which does not comply with these terms. 